again it completely blocked the effects of $2 \mu \mathrm{g}$ of noradrenaline. 'Two minutes later, when propranolol had been washed out, $2 \mu \mathrm{g}$ of noradrenaline was again effective.

When, on the other hand, the temperature was increased to $30^{\circ}-34^{\circ} \mathrm{C}$ in the winter frog heart, the blocking capacity of the beta blocking agent pronethalol remained unchanged, or even increased in some cases, as compared with the diminishing or complete disappearance of the blockade produced by the alpha blocking agent phentolamine in the same experiments.

The principal trends induced by altering the metabolic milieu are summarized in Fig. 3. The degree of blocking capacity of the antagonists is expressed in all cases in terms of the $\log$ of the dose ratio, which is the ratio of effective threshold dose of adrenaline before and after blockade. When the temperature is Iowered from $22^{\circ}-$ $24^{\circ} \mathrm{C}$ to $5^{\circ}-10^{\circ} \mathrm{C}$ in the summer frog heart (Fig. $3 \mathrm{~A}$ ), the beta blocking capacity disappears, as shown by a significant decrease in the blockade, from $1.95 \pm 0.43$ to $0 \cdot 67 \pm$ 0.39 produced by pronethalol. In all cases, the dose of blocking agent remained unaltered in one and the same experiment. On the other hand, raising the temporature from the initial level to $30^{\circ}-34^{\circ} \mathrm{C}$ (Fig. $3 B$ ) resulted in a
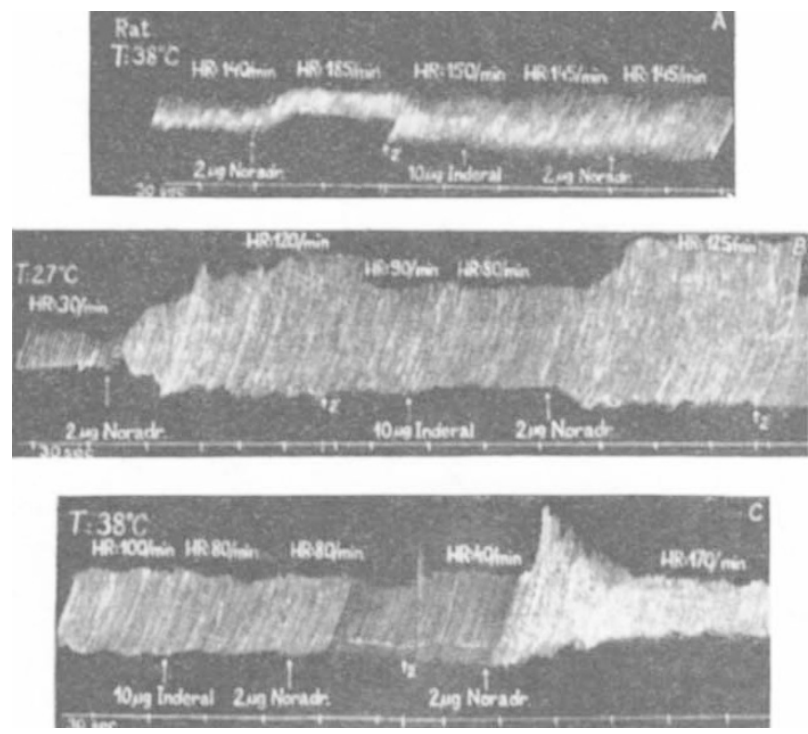

Fig. 2. Isolated rat heart. Influence of change of temperature on the blockade of the myocardial effects of noradrenaline by $5 \mu \mathrm{g}$ of propranolol. Time signal: $30 \mathrm{~s}$. H.R, Heart rate. For explanation,
A

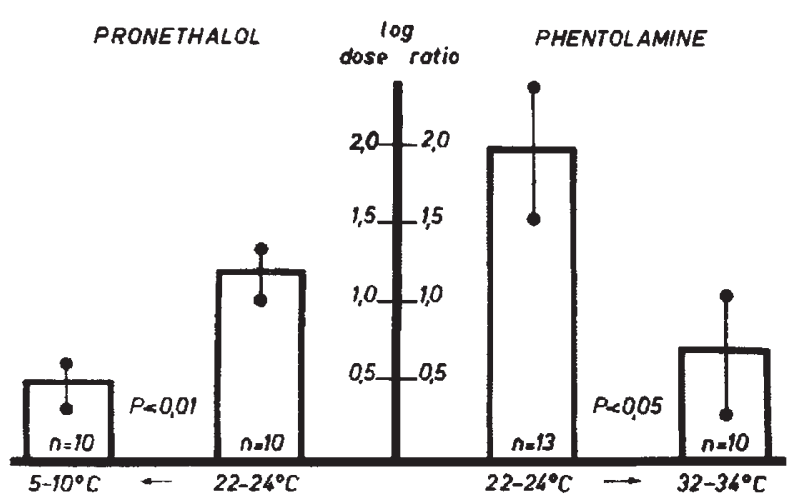

Fig. 3. $A$, Degree of blockade of adrenaline effect by $2-4 \times 10^{-8} \mathrm{M}$ pronethalol at $22^{\circ}-24^{\circ} \mathrm{C}$ and $5^{\circ}-10^{\circ} \mathrm{C}$ in the summer frog heart. $B$, Degre of blockade of adrenaline effect by $3 \times 10^{-8}-2 \times 10^{-7} \mathrm{M}$ phentolamine at $22^{\circ}-24^{\circ} \mathrm{C}$ and $32^{\circ}-34^{\circ} \mathrm{C}$ in the winter frog heart. Ordinate: log (doser ratio) of adrenaline sensitivity before and after blockade. $n$, Number of experiments; $P$, probability ratio. Vertical lines: standard error. decrease of the alpha blocking capacity, shown by a decrease in the blockade produced by phentolamine from $1 \cdot 18 \pm 0 \cdot 17$ to $0 \cdot 48 \pm 0 \cdot 13$.

If these two trends are the results of different sensitivity of a single receptor, then there must be a state in which both types of blocking agonts are equally and separately active; this was found in the case of the winter frog heart at $22^{\circ}-24^{\circ} \mathrm{C}$. This latter finding is incongruous with another possibility, that tissues can contain both alpha and beta receptors, with one predominating. If this were so, the greatest difference in the two kinds of blockades should have been found at room temperature, the temperatures at which frogs were previously kept and to which they had presumably become adapted. In this hypothetical case, only the combined administration of the two types of blocking agents could have produced an inhibitory effect instead of acting separately.

It can therefore be stated that the prerequisites for the existence of a metabolically influenced single adrenergic receptor-as far as myocardium is concerned-have been fulfilled in the present experiments.

\section{(t. Kunos}

M. Szentivanyi

'Third Department of Medicine,

University Medical School,

Budapest, Hungary.

Received December 28, 1967 ; revised February 7, 1988.

${ }^{1}$ Ahlquist, R., J. Pharmaceut. Sci., 55, 359 (1966).

${ }^{2}$ Amsler, C., Pfiüger's Arch. Ges. Physiol, 185, 86 (1920).

\section{GENERAL}

\section{Recognition of Syntactic Structure by Computer}

THE recent article concerning computer simulation ${ }^{1}$ is refuted by its first sentence. As the first condition for an acceptable simulation of the way in which human beings recognize syntactic structure, the authors say "an analyser must not be dependent on looking up every word of an input sentence in a dictionary". To meet this condition a dictionary is used which contains information "only about those words with fixed syntactic functions and about suffixes". "With this dictionary alone, infinitely many English sentences can be analysed." Unfortunately, there are also "infinitely many" sentences which cannot be analysed in this way. The first sentence of the article is one such sentence.

This sentence is: "An essential part of the capacity to understand utterances lies in the ability to recognize syntactic structure". Any English-speaking reader can refute the article by playing the following simple game. First, rewrite the sentence keeping the pronouns, conjunc. tions and prepositions and substituting for other (nonfixed syntax) words an $X$ plus the endings -s, -ed and -ing (if they appear). Second, the reader must try to replace $X_{s}$ by words which have a different syntactic function from the word in the original sentence. For example, the sentence is rewritten as "An $X X$ of the $X$ to $X X$ s $X_{\mathbf{s}}$ in the $X$ to $X X X$ ". For the first two $X_{\text {s }}$ the noun-verb combination "actor knew" can be substituted for the adjective-noun combination "essential part". Whenever such a substitution can be made, the reader wins and the computer programmo loses.

IRwIN D. J. Bross

Roswell Park Memorial Institute,

Buffalo,

New York.

Received January 19, 1968.

1 Bratley, P., Dewar, H., and Thorne, J. P., Nature, 216, 969 (1967). 